\title{
LABORATÓRIO DIALOGAL FÉ E RAZÃO: UM ENCONTRO POSSÍVEL NO ÂMBITO UNIVERSITÁRIO
}

\author{
Virgínia Caeli Castro Azevedo ${ }^{1}$, Anna Luísa do Nascimento Ferreira ${ }^{2}$, Paula Márcia Seabra de \\ Sousa $^{3 *}$, Patrick Wagner de Azevedo ${ }^{3}$ \& Pe. Murialdo Gasparet ${ }^{3}$
}

\begin{abstract}
RESUMO
AZEVEDO,V. C.C., FERREIRA, A. L. N., SOUSA, P. M. S., AZEVEdO, P.W.,GASPARET, Pe. M. Laboratório Dialogal Fé e Razão: Um Econtro Possível no Âmbito Universitário. Perpectivas Online: Humanas \& Sociais Aplicadas, v.7, n.19, p.23-30, 2017.
\end{abstract}

Trata-se de um espaço criado, nos Institutos Superiores de Ensino do CENSA, para questionamentos, diálogos, buscas científica e humana, onde ciência e religião possam se encontrar de maneira acadêmica e ética. A metodologia utilizada foi a Revisão Sistemática de Literatura desenvolvida nos últimos dez anos, publicadas em português em Revistas Indexadas no Scielo, utilizando como descritores: Fé, Razão e Religião. Foram recuperados três artigos científicos e, por essa limitação quantitativa, também recorremos a obras literárias voltadas para temática. O objetivo desse primeiro projeto foi proporcionar o encontro e o diálogo entre religião e ciência, sendo algo engrandecedor para a humanidade, na medida em que essas realidades,

Palavras-chave: Fé; Razão; Religião. de alguma forma, estão intrinsecamente ligadas à vida humana. Os resultados apresentados nos levam a compreender que o questionamento traz um movimento ao ser humano, tendendo a tornarse pesquisa e ciência. Por outro lado, a religião, de alguma forma, perpassa a vida do ser humano, traz desejos, inspirações, questionamentos e conflitos, deparando-se, assim, com a ciência. O homem deseja, por natureza, superar todas as suas dificuldades e vive em busca de respostas, querendo desvendar todos os mistérios da vida. Acreditamos, com esse projeto, contribuir para um melhor entendimento sobre religião versos razão, bem como a interação e união das mesmas dentro da ética. 


\begin{abstract}
The "Laboratório dialogal fé e razão" is a place created, in ISECENSA, to solve questions, make dialogues, scientific and human researches; where science and religion can get together in an academic and ethic way. The methodology used was the Systematic Literature Review, developed in the past 10 years, published in Portuguese in magazines indexed on Scielo, using as arguments: Faith, Rationality and Religion. Three scientific articles were regained and, due this measurable limitation, we also fell back on literacy works that are about this theme. The objective of this first project was to provide the rendezvous and the dialogue between religion and science, being something enhanced to the humanity, in degree

the human life. The results presented let us understand that, the questions we make move the human beings forward, tending to become research and science. On the other hand, the religion, in some way, is beyond the human being's life; it brings desire, inspiration, questions and conflicts, facing, in that way, science. The human beings crave, for their own nature, to overcome all of their difficulties and they live looking for answers, wishing they could solve all the mysteries of life. We believe that with this project, we will contribute with a better understanding about religion versus rationality, as well the interaction and union between them inside ethic.
\end{abstract} that these realities, in some way, are connected to

Keywords: Faith; Reason; Religion.

\footnotetext{
${ }^{1}$ Acadêmica em Psicologia ISECENSA - Institutos Superiores de Ensino do CENSA - ISECENSA - Rua Salvador Correa, 139, Centro, Campos dos Goytacazes, RJ, CEP: 28035-310, Brasil;

${ }^{2}$ Acadêmica em Pedagogia ISECENSA - Institutos Superiores de Ensino do CENSA - ISECENSA - Rua Salvador Correa, 139, Centro, Campos dos Goytacazes, RJ, CEP: 28035-310, Brasil;

${ }^{3}$ Institutos Superiores de Ensino do CENSA - ISECENSA - Laboratório Dialogal Fé e Razão - Rua Salvador Correa, 139, Centro, Campos dos Goytacazes, RJ, CEP: 28035-310, Brasil;

(*)e-mail: paulamseabra@yahoo.com.br

Data de chegada: 19/04/2017 Aceito para publicação: 09/06/2017
} 


\section{INTRODUÇÃO}

A Pastoral Universitária dos Institutos Superiores de CENSA tem o compromisso de se estender em todas as áreas universitárias onde o ser humano se encontre, tendo como missão o encantamento pelo outro, pela fé e pelo bem. Dessa forma, ela também pode atrair o universitário, por meio de um diálogo científico, humano e ético. Por essa razão, foi formada uma equipe interdisciplinar de professores e alunos que atuaram na universidade no ano de 2016, através do diálogo entre a razão e a fé, dentro da perspectiva de Dom Bosco, pai e mestre da juventude. Ele revelou em toda a sua vida um envolvimento e uma paixão por Jesus, por meio de seus serviços com os jovens, dedicando a esses o seu sacerdócio. Sua identidade fora construída baseada nos valores transmitidos por sua família, como ressalta Artime (2015):

A sabedoria campesina, a argúcia saudável, o sentido do trabalho, a essencialidade das coisas, a diligência na ação, o otimismo a toda prova, a resistência nos momentos de desventura, a capacidade de recomeçar depois dos reveses, a alegria sempre de qualquer maneira, o espírito de solidariedade, a fé viva, a verdade e a intensidade dos afetos, o gosto pela acolhida e a hospitalidade, bens todos eles que encontrara em sua casa e o construíram daquela maneira. (ARTIME, 2015, p.38).

No ano de 1859, em um contexto europeu de crescente secularização, Dom Bosco fundou a congregação salesiana, em Turin - Itália (MONTERO, 2007), respaldada nos ideais de São Francisco de Salles que tinha como lema Da mihi animas, cetera tolle, que significa "dá-me as almas, ficai com o resto". Para Villanueva (2014), a espiritualidade se reveste de um conjunto de valores e atitudes que não servem somente as igrejas, mas a sociedade como um todo. O serviço salesiano é guiado pelo desejo de seguir a Deus e pela alegria de enxergar no jovem a transformação que o mundo precisa. É além de tudo acreditar no ideal de Dom Bosco: o jovem e seu potencial. Para ensinar e conviver com estes jovens, Dom Bosco cria um sistema educativo que transcende o seu tempo e permanece nas instituições salesianas na atualidade em todas as partes do mundo.

O sistema preventivo tem como princípios os valores humanos, religiosos e afetivos, e assim sendo está assentado em três vigas mestras: a razão (carinho racional e amor equilibrado, não se confundindo com sentimentalismo), a religião (pedagogia sobrenatural e humana, onde a honra e amor a Deus é o princípio, meio e fim de toda formação da pessoa humana) e a amorevolezza (é o carinho, a caridade, a confiança no educador e a familiaridade). (ALKIMIN 2014, p.11).

O ser humano tem uma profunda sede de sentidos, vive em busca de algo, de respostas, de sonhos. É essa falta que impulsiona a pessoa a viver e, muitas vezes, a buscar a Deus. O Laboratório Dialogal: Fé e Razão é um laboratório que sempre vai estar em movimento, se construindo, em razão da própria natureza inacabada e aberta do ser humano. A sua criação e o desenvolvimento de pesquisas científicas vai, justamente, ao encontro do sonhado e vivido por Dom Bosco, porém, dentro da realidade contemporânea, dando continuidade a vivência do carisma salesiano.

Dessa forma, a realidade da fé e da razão vem para dialogar e não para brigar. Uma vez que existe uma suposta incompatibilidade entre fé e razão, a academia precisa enfrentar o pensamento moderno da racionalidade pura, do secularismo, podendo levar o ser humano a perder o olhar humanizador e proporcionar o encontro com o outro, com o diferente, com o transcendente e, até mesmo, com a sua própria pessoa, na busca pela solidariedade, ética, justiça e paz. "Cristo não ensina nenhuma ética abstrata que deva ser praticada a qualquer custo. Ele não foi essencialmente um mestre, um legislador, e sim um ser humano, um homem verdadeiro como nós". (FORTE, 2006, p. 118-119).

O papa João Paulo II, tendo em vista a importância da reflexão entre fé e razão, em 14 de setembro de 1998, promulgou a carta encíclica "Fides et Ratio" (Fé e Razão), que tem como objetivo refletir sobre a importância dessas duas dimensões que perpassa o ser humano, fazendo com que os formadores de opinião (pesquisadores, professores, filósofos e teólogos e etc.) se empenhem para buscar um pensamento que harmonize fé e razão, dando ao ser humano condições de responder aos apelos mais profundos de sua existência (JOÃO PAULO II, 1998). 
Em auxílio da razão, que procura a compreensão do mistério, vêm também os sinais presentes na Revelação. Estes servem para conduzir mais longe a busca da verdade e permitir que a mente possa autonomamente investigar inclusive dentro do mistério. De qualquer modo, se, por um lado, esses sinais dão maior força à razão, porque lhe permitem pesquisar dentro do mistério com os seus próprios meios, de que ela justamente se sente ciosa, por outro lado, impelem-na a transcender a sua realidade de sinais para apreender o significado ulterior de que eles são portadores. Portanto, já há neles uma verdade escondida, para a qual encaminham a mente e da qual esta não pode prescindir sem destruir o próprio sinal que lhe foi proposto (JOÃO PAULO II, 1998).

Sabe-se que a razão orienta a ciência na busca de descobertas, de questionamentos emergentes na sociedade, que impulsiona o desenvolvimento da humanidade. No entanto, a fé é para todos que creem uma luz que ilumina os momentos difíceis, os momentos em que respostas não acontecem, onde a ciência cai no silêncio. Assim, a razão serve a ciência em suas descobertas, nutre a inteligência humana. Já a fé, nutre a vida espiritual de toda pessoa. Não é compreensível a razão caminhar sem a fé, uma vez que, onde a razão humana com toda sua capacidade intelectual não consegue chegar, a fé perpassa o ser humano como uma luz condutora, fornecendo compreensão ao invés de respostas racionais.

O Objetivo do nosso estudo foi fomentar o diálogo intercultural entre fé e razão, preparando alunos e professores do ISECENSA não somente para o conhecimento de uma profissão, mas também para a busca de uma visão ampla da vida humana, juntamente com todas as suas inquietudes a caminho de uma sociedade mais livre, solidária e cidadã.

\section{METODOLOGIA}

A metodologia utilizada na presente pesquisa foi a de Revisão Sistemática da Literatura, pois esse método nos ajudou a colher dados científicos sobre o tema estudado para, posteriormente, guiar a nossa prática. Por essa razão, tal método é muito utilizado e recomendado. Foi realizada uma investigação na base de dado da Scientific Electronic Library Online - Scielo e selecionado artigos científicos publicados em português, no período de 2006 a 2016, utilizando os seguintes descritores: Fé, Razão e Religião. Foram capturados apenas três artigos científicos e, por essa limitação, o estudo também se baseou em literaturas pertinentes à temática proposta.

\section{DESENVOLVIMENTO}

Conforme a metodologia utilizada foi selecionado cinco artigos científico, no entanto, apenas três em eram em língua portuguesa:

\begin{tabular}{|c|c|c|c|c|c|}
\hline Autor & $\begin{array}{c}\text { Título do } \\
\text { Artigo }\end{array}$ & Resumo & $\begin{array}{l}\text { Metodo- } \\
\text { logia }\end{array}$ & Ano & Revista \\
\hline $\begin{array}{c}\text { JOAS, } \\
\text { Hans. }\end{array}$ & $\begin{array}{c}\text { A } \\
\text { secularização } \\
\text { conduz à } \\
\text { decadência } \\
\text { moral? }\end{array}$ & $\begin{array}{l}\text { Os debates sobre ética e religião, sobre } \\
\text { significância da fé na mediação dos valores e da } \\
\text { coesão social, e sobre risco das religiões para a } \\
\text { tolerância e a coexistência pacífica tendem a ser } \\
\text { distorcidos em razão de deficiências empíricas. }\end{array}$ & $\begin{array}{l}\text { Revisão } \\
\text { de } \\
\text { Literatu- } \\
\text { ra }\end{array}$ & 2015 & $\begin{array}{l}\text { Sociolo-gias, } \\
\text { Porto } \\
\text { Alegre, ano } \\
17, \mathrm{n}^{\circ} 39 .\end{array}$ \\
\hline $\begin{array}{l}\text { MAIA } \\
\text { NETO, } \\
\text { José R. }\end{array}$ & $\begin{array}{l}\text { As Principais } \\
\text { Forças dos } \\
\text { Pirrônicos (La } \\
\text { 131) e sua } \\
\text { Apropriação } \\
\text { por Huet }\end{array}$ & $\begin{array}{c}\text { Este artigo tem duas partes. Na primeira, é } \\
\text { examinada a } \\
\text { apropriação que Pascal faz do argumento } \\
\text { cartesiano do Deus enganador no } \\
\text { fragmento La } 131 \text { dos Pensamentos. Na segunda } \\
\text { parte, é examinada } \\
\text { a apropriação que Huet faz deste mesmo } \\
\text { argumento cartesiano no seu } \\
\text { Tratado filosófico da fraqueza do entendimento } \\
\text { humano. }\end{array}$ & $\begin{array}{l}\text { Revisão } \\
\text { de } \\
\text { Literatu- } \\
\quad \text { ra }\end{array}$ & 2006 & $\begin{array}{l}\text { KRITERIO } \\
\text { N, Belo } \\
\text { Horizonte, } \\
\mathrm{n}^{\circ} 114\end{array}$ \\
\hline
\end{tabular}

Persp. online: hum. \& sociais aplicada., Campos dos Goytacazes, 19 (7), 23-30, 2017

seer.perspectivasonline.com.br 


\begin{tabular}{|c|c|c|c|c|c|}
\hline $\begin{array}{c}\text { TOTARO, } \\
\text { Paolo }\end{array}$ & $\begin{array}{l}\text { O Misticismo } \\
\text { do Cálculo e a } \\
\text { Ascese } \\
\text { Consumista - } \\
\text { Razão e Fé No } \\
\text { "Crer Sem } \\
\text { Pertencer" e } \\
\text { no } \\
\text { Neopentecosta } \\
\text {-lismo. }\end{array}$ & $\begin{array}{l}\text { A cultura do cálculo engendra duas formas de } \\
\text { individualização: 1) o isolamento } \\
\text { do indivíduo como "peça" nos processos } \\
\text { formalizados (nos repetitivos ciclos do } \\
\text { consumo e na lógica organizacional da } \\
\text { burocracia), o qual coloca a consciência } \\
\text { numa condição de heteronomia; 2) a liberdade } \\
\text { do homem decorrente da possibilidade } \\
\text { de controlar a natureza física e social, que } \\
\text { desenvolve uma condição de autonomia } \\
\text { da consciência. }\end{array}$ & $\begin{array}{c}\text { Pesquisa } \\
\text { de } \\
\text { Campo }\end{array}$ & 2010 & $\begin{array}{c}\text { Religião e } \\
\text { Sociedade, } \\
\text { Rio de } \\
\text { Janeiro, } \\
30(1)\end{array}$ \\
\hline
\end{tabular}

Na modernidade o ser humano chegou a pensar que a luz da fé, que serviu a humanidade antiga, não era mais eficaz, cabida ou atual para esse tempo, onde a razão e o saber ganharam poder, orgulho e onipotência. "Nesse caso, a fé seria uma espécie de ilusão de luz, que impede o nosso caminho de homens livres rumo ao amanhã" (LF, $\left.\mathrm{n}^{\circ} 2\right)$. Foram muitos os debates enfrentados por grandes filósofos e pensadores ao da história da humanidade sobre fé e razão:

Embora Pascal considere, como Huet, que o cristianismo não pode ser provado pela razão, embora ambos mantenham um distanciamento crítico da teologia natural, Pascal não é fi deísta como Huet. Os argumentos pascalianos não se reduzem às provas históricas baseadas nas profecias e milagres. Pascal elabora também o argumento da verdadeira religião ou prova pela doutrina, que, embora não demonstre a verdade do cristianismo, atribui-lhe um poder explicativo racional. (MAIA NETO, 2006, p. 254).

O secularismo é um sentimento ou atitude de estabelecer uma separação entre o campo humano e o campo religioso e, muitas vezes, induz o pensamento de que só se pode afirmar algo como humano se ocorrer a ruptura com o divino. De forma contrária a esse pensamento, Santo Agostinho (1973) busca não opor Teologia e Filosofia e afirma: "vemos o homem, criado à Vossa imagem e semelhança, constituído em dignidade acima de todos os viventes irracionais, por causa de vossa mesma imagem e semelhança, isto é, por virtude da razão e da inteligência". (Apud. SILVA, 2006, p. 45). Totaro (2009) afirma que a cultura do cálculo forma duas formas de individuação:

A cultura do cálculo, que marcou a chamada racionalidade moderna, engendra duas formas de individualização: a primeira, constituída pela inserção dos homens em processos formalizados, é acompanhada por um estado de heteronomia da consciência (na burocracia e na cultura do consumo); a segunda, em que o cálculo atua como linguagem de representação e síntese teórica do mundo, favorece um estado de autonomia da consciência frente aos desafios da "natureza" física e social. (TOTARO, 2009, p. 84).

No entanto, pensar no amanhã é pensar no futuro, pensar no futuro é pensar em incertezas. É aqui que o ser humano depara-se com seus limites, com seus vazios, com suas inseguranças, mas também com possibilidades, com a esperança e com a fé. A humanidade caminha juntamente com o desenvolvimento da ciência e seus questionamentos, levando também ao crescimento da própria Filosofia, das Ciências Sociais, Políticas e Humanas.

O documento 102 da Conferência Nacional dos Bispos do Brasil (CNBB) destaca que quanto maior for a disponibilidade de diálogo entre fé e razão, e o empenho na capacitação de leigos inseridos em sua própria realidade pessoal e profissional, maior será a conscientização e mais saudável será a sociedade (CNBB, 2013). Dessa forma pontua que "Promover o diálogo crítico com a cultura de nosso tempo, denunciando, por meio do testemunho da vida cristã, o reducionismo e a pequenez do modelo economicista, consumista, individualista e hedonista." (CNBB, 2013, p. 17). A fé não só ilumina nossos passos, nossa razão, mas também abre nossos caminhos, nos impulsiona na abertura para o outro e para o Outro, nos faz sair de nós mesmos, do nosso mundo individual e solitário para um mundo comunitário e fraterno. A fé ilumina o caminho, mas não tira a liberdade, o discernimento, nem a razão do ser humano, pelo contrário, clarifica a razão. 
É perfeitamente racional pensar que fé e ciência se necessitem mutuamente. Enquanto a ciência livra a fé da ingenuidade, a fé pode ajudar a ciência a não cair num puro materialismo. A fé precisa da luz da ciência para não ser cega e não se tornar fanática e doentia; a ciência precisa da fé para não colocar as suas descobertas a serviço da destruição humana. (Setor Universidades, 2011, p. 18).

A fé que nos é fornecida por Deus não se fecha à compreensão, pelo contrário, ela advém da acolhida da verdade do amor. A pessoa só consegue compreender o amor quando ama, sem antes abrir-se para ele, não é possível saber da sua existência. Um amor duradouro é verdadeiro, por isso, o tempo comprova a sua existência. Além disso, é impossível viver um amor sem a existência do outro, pois para amar a nós mesmos e ao próximo, imprescindivelmente, precisamos primeiro nos deixar sermos amados. Eis a verdade da fé.

$\mathrm{Na}$ cultura contemporânea se aceita como verdade apenas aquela que provém da tecnologia, do mensurável, da concretude e da objetividade da ciência, por ser uma verdade mais visível, cômoda e aprazível. Existem as verdades do sujeito, que advém da sua autenticidade e que são válidas. No entanto, apenas para a pessoa, pois não podem ser apresentadas para os outros como único critério de validade. Aquela verdade maior, que nos é proposta como explicação da vida pessoal e social, é vista com suspeita devido aos grandes sistemas totalitários, que serviram para ferir e aniquilar a história da humanidade, voltando-se para uma uniformização social. Nessa lógica, a religião foi afetada e relativizada, sendo vista como a raiz do fanatismo, não respeitando as diferenças.

até agora, não é possível demonstrar que a secularização conduza à decadência moral. Em parte, isso pode resultar da persistência de orientações morais que emanam de um imaginário religioso, mas que mantêm sua força apesar de desligadas dessa base de formação. Contudo, parece ser decisivo que as próprias estruturas de cooperação humana ou conduzem os indivíduos à manutenção de compromissos de reciprocidade por razões de interesse próprio ou os sensibilizam para o valor da justiça. Este e outros valores moralmente relevantes podem inspirar compromisso através de experiências positivas - sua incorporação em modelos, por exemplo - ou de experiências negativas - como a vivência de injustiça, degradação ou violência. (JOAS, 2015, p. 243).

$\mathrm{Na}$ medida em que a preocupação da modernidade voltou-se para a luta contra a religião, a "escuridão", no âmbito da memória da humanidade, foi se fazendo presente. "De fato, a busca da verdade é uma questão de memória, de memória profunda, porque visa algo que nos precede e, desta forma, pode conseguir unir-nos para além do nosso "eu" pequeno e limitado; é uma questão relativa à origem de tudo, a cuja luz se pode ver a meta e também o sentido da estrada comum" (LF, $\left.\mathrm{n}^{\circ} 25\right)$. A fé nos ajuda a sairmos do nosso egoísmo e irmos ao encontro do outro, iluminando o caminho da própria comunidade que a aceita. "A fé ilumina também as relações entre os homens, porque nasce do amor e segue a dinâmica do amor de Deus" $\left(\mathrm{LF}, \mathrm{n}^{\mathrm{o}} 50\right)$. Ela abre espaços na mente humana para o perdão, encontrando razões verdadeiras para perdoar. A fé que o sujeito possui é capaz de, unindo-se a sua razão, ressignificar a própria vida, como também dar sentido ao sofrimento, sabendo que esse é inevitável à vida humana. "A fé não é luz que dissipa todas as nossas trevas, mas lâmpada que guia os nossos passos na noite, e isto basta para o caminho" (LF, no 57). Por essas razões que a fé se une à esperança e à caridade. "Quando o homem pensa que, afastando-se de Deus, encontrar-se-á a si mesmo a sua existência fracassa" (Lc. 15, 11-24).

\section{CONSIDERAÇÕES FINAIS}

O ser humano não deve perder a vontade e o desejo de investigar, o interesse em descobrir, em saber, visto a sua necessidade de estar construindo sempre e de buscar novas respostas para seus questionamentos. Ele almeja o saber. Por essa razão que novas perspectivas de construção do conhecimento quando apresentadas ao ser humano são por ele exploradas. Quando o objetivo da pesquisa apresentada é o progresso e o bem estar da própria humanidade a união de interesses é grandiosa, pois ao mesmo tempo em que sacia a sede de saber, ele se realiza no avanço humanitário. Esse desejo de alcançar a verdade deve ser valorizado e incentivado pelas instituições de ensino, acreditando no ser humano como agente capaz de transformação.

Persp. online: hum. \& sociais aplicada., Campos dos Goytacazes, 19 (7), 23-30, 2017

seer.perspectivasonline.com.br 
A fé passa pela experiência do amar, do escutar, do ver e do tocar. Essa escuta da fé é algo pessoal, que exige uma abertura de coração e atenção aos fatos, acontecimentos e encontros de nossas vidas. Santo Agostinho quando comenta a passagem bíblica da mulher que toca Jesus para ser curada da sua hemorragia (cf. Lc 8, 45-46) afirma: "Tocar com o coração, isto é crer" (Sermo 229/L, 2: PLS 2, 576. In: LF, no 31). O ser humano é um ser de relações, de abertura e inacabado. A ciência é medida, mensurada e pesquisada, fundamentada na razão. Apesar disso, ela também não tem fim, não se esgota na certeza e no encerramento de uma pesquisa, ela leva o ser humano a novas dúvidas, novos questionamentos, novas aberturas no horizonte científico. A vida humana é um mistério que a ciência estuda, chegando a conclusões importantíssimas e avançando científica e academicamente, porém depara-se sempre com um limite, onde a razão não mais consegue compreender. Assim, a fé também ilumina a vida em sociedade. Ela nos chama a comunhão fraterna, a solidariedade e ao amor, pois ela não pode ser vivida isoladamente, assim como o amor, ou em uma relação entre o "eu" e um "tu" divino e, passando por Deus, ela passa, obrigatoriamente, por toda a humanidade.

Acredita-se que com o incentivo às pesquisas envolvendo fé e razão, entrelaçando conhecimentos que dizem respeito aos mais profundos questionamentbos de todos os seres humanos, muitas outras irão surgir, dando seguimento a este campo, com diálogos profundos e engrandecedores, com a literatura científica e o meio social, resultando em produções de artigos científicos.

\section{REFERÊNCIAS}

ALKIMIN, M. A.; NASCIMENTO, G. A. F. O sistema educativo de Dom Bosco e a concretização da Educação em Direitos Humanos. 2014.

ARTIME, A. F. Estreia 2015: Como Dom Bosco, com os jovens, para os jovens! São Paulo: Ed Dom Bosco, 2015.

VILlanUeVA (SDB), Pe. Pascual Chávez. Da mihi animas, cetera tolle. Comentário do Reitor-Mor, 2014. Disponível em: http://vocacional.salesianos.br/wp-content/uploads/2014/01/ESTREIA-2014.pdf. Acesso em: 23 mai. 2016.

CNBB, Conferência Nacional dos Bispos do Brasil. O Seguimento de Jesus Cristo e a Ação Evangelizadora no Âmbito Universitário. Brasília: CNBB, 2013.

SETOR UNIVERSIDADES. Roteiros de Reflexão Para Universitários: Uma experiência. Brasília: CNBB, 2011.

FORTE, B. Um pelo outro: por uma ética da transcendência. São Paulo: Paulinas, 2006.

MONTERO, Paula. Antonio Colbacchini e a etnografia salesiana. Rev. bras. Ci. Soc., São Paulo, v. 22, n. 64, p. 49-63, June 2007. Disponível em: <http://www.scielo.br/scielo.php?script=sci_arttext\&pid=S010269092007000200004\&lng=en\&nrm=iso>. Acesso em: 20 abr. 2016.

JOÃO PAULO II. Fides et Ratio: Sobre as relações entre fé e razão. Disponível em: http://w2.vatican.va/content/john-paul-ii/pt/encyclicals/documents/hf_jpii_enc_14091998_fides-etratio.html. Acesso em: 26.03.2016.

JOAS, Hans. A secularização conduz à decadência moral?. Sociologias, Porto Alegre, v. 17, n. 39, p. 224246, Ag. 2015. Disponível em: <http://www.scielo.br/scielo.php?script=sci_arttext\&pid=S1517$45222015000200224 \& \operatorname{lng}=$ en\&nrm=iso $>$. Acesso em: 29 jun. 2016.

MAIA NETO, José R.. As principais forças dos pirrônicos (La 131) e sua apropriação por Huet. Kriterion, Belo Horizonte, v. 47, n. 114, p. 237-257, Dez. 2006. Disponível em: $<$ http://www.scielo.br/scielo.php?script=sci_arttext\&pid=S0100-512X2006000200004\&lng=en\&nrm=iso $>$. Acesso em: 29 jun. 2016. 
PAPA FRANCISCO. Carta Encíclica Lumen Fidei. Loyola: São Paulo, 2013.

SILVA, Cleverson Suzart. Reflexões sobre conhecimento, poder, educação e antropofagia: o inesperado talvez . Tese (doutorado) - Universidade Federal da Bahia. Faculdade de Educação, Salvador, 2006. Disponível em: https://repositorio.ufba.br/ri/bitstream/ri/18280/1/Tese_Cleverson_pdg.pdf. Acesso em: 20 ago. 2016.

TOTARO, Paolo. Misticismo do cálculo e a ascese consumista: razão e fé no "crer sem pertencer" e no neopentecostalismo. Relig. soc., Rio de Janeiro, v. 30, n. 1, p. 81-100, Jul. 2010. Disponível em: $<$ http://www.scielo.br/scielo.php?script=sci_arttext\&pid=S0100-85872010000100005\&lng=en\&nrm=iso $>$. Acesso em: 29 Jun. 2016. 